\title{
Forming Mechanism of a Seedling Tray Comprised of Lignocellulose in Cow Manure
}

\author{
Bo Zhang, ${ }^{a}$ Wei Zhang, ${ }^{\mathrm{b}, *}$ Yongcai Ma, ${ }^{\mathrm{b}}$ Liqiang Qi ${ }^{\mathrm{b}}$ and Jianfei Shi ${ }^{\mathrm{a}}$
}

\begin{abstract}
A new method for producing biomass seedling trays with cow manure was developed based on heating to above the glass transition point of the lignin in cow dung. The maize seedling tray, manufactured through heat compression molding, could potentially meet the demand for transplanting maize seedlings. A scanning electron microscope and universal testing machine were used to compare the changes in the internal structure and mechanical properties of the seedling tray before and after the seeding period through a compression molding technique at normal temperature before seeding and a heat compression molding technique after seeding. The results showed that the strength of the seedling tray was mainly derived from the mechanical setting force of the fiber laminated in the seedling tray. Meanwhile, the moisture in the seedling tray hindered the lignin from filling in the gaps between the stem fibers in cow manure, as well as it reduced the protective effect of lignin on the laminated inlay structure of the stem fibers in cow manure. Therefore, under the premise that the material could be completely filled in the mold, the study concluded that a lower moisture content resulted in better strength and water resistance of the seedling tray. As such, this study provides an idea for the functional utilization of cow manure.
\end{abstract}

Keywords: Lignin; Plug seedings; Biomass; Cow dung; Bond

Contact information: a: College of Electrical and Information, Heilongjiang Bayi Agricultural University, Daqing 163319, China; b: College of Engineering, Heilongjiang Bayi Agricultural University, Daqing 163319, China; *Corresponding author: zhang66wei@ 126.com

\section{INTRODUCTION}

The dairy cattle industry of China has developed rapidly in recent years. As the farm scale expands daily, the accompanying manure pollution has seriously restricted the sustainable development of the dairy cattle industry. According to the cow's daily defecation weight measurement, results indicate a cow's daily manure is $5 \%$ to $6 \%$ of its weight. Consequently, if a cow's weight is $450 \mathrm{~kg}$, it will discharge $25 \mathrm{~kg}$ of dung a day on average, resulting in up to $9000 \mathrm{~kg}$ of dung a year (Nennich et al. 2005). As a result of this magnitude, the rational use of cow dung has become a critical problem that needs to be promptly resolved.

Heilongjiang is a vast region serving as the main maize producing area in China. Field sowing is the traditional maize planting mode. Due to the high latitude, the short frost-free season leads to a short growing period of maize in Heilongjiang. Therefore, the maize planted in the traditional way has poor quality and low yield. To extend the growing period of maize, transplanting seedlings has frequently been adopted in recent years. In this method, seeds are first sown in seedling trays in a seedling cultivation greenhouse, and then they are replanted to the field after seedling emergence. Transplanting seedlings could increase the growing period of maize 15 days to 20 days, thus effectively improving the 
quality and yield of the maize (Fang 2010). The existing maize seedling trays are mostly plastic, have a short use cycle, and are not environmentally friendly (Zhang and Zhang 2000; Nunomura et al. 2016). As such, in these trays the seedlings need to be taken from the hole and then transferred into the field. This process is complex, making it difficult for promotion, application, and the achievement of mechanized and large-scale production (Wei et al. 2015). Nevertheless, the tray seedlings do not need to be removed when the seedling tray is made from biodegradable materials, where the seedling tray can be directly replanted into the field together with the tray seedlings; this not only simplifies the replanting process but is also more environmentally friendly (Ma et al. 2016).

There is a large amount of lignin and cellulose in cow dung. The degradable seedling tray manufactured with cow dung not only can simplify the structure of the supporting replanting machine and promote the application of seedling replanting technology, but also it can provide solutions for the functional use of cow dung. Currently, cow dung is mainly used as forage, energy, and fertilizer (Anthony 1970; Eghball 2000; Sreekrishnan et al. 2004). As feedstuff, cow dung is mainly obtained through mechanical drying, but it is easy to lose nutrients and cause secondary environmental pollution through this method due to a large one-time investment of energy consumption. Although the biofermented cow dung fodder has good palatability, high digestibility, and the absence of a peculiar smell, many undesired ingredients are present in the dung due to the extensive use of additives in the production process of livestock and poultry. As a result, when the dung is used as a fodder again, the problem of exceeding standards or even poisoning may occur (Zhao and Gong 2000). Because the energy from cow dung is mainly used to produce biogas through anaerobic fermentation, the excess residues become a huge problem that restricts the development of cow dung in improving biogas output. Moreover, the engineering cost and investment for biogas is generally high, and the running effect is influenced by temperature and season, thereby restricting its popularization in some regions, especially the northern areas during the winter months (Song et al. 2002). Traditionally, cow manure is most utilized across the world as fertilizer, which not only effectively utilizes the organic matter, nitrogen, phosphorus, and some trace elements in the cow manure, but also serves as a low-cost option with a large processing amount. Nevertheless, from an economic perspective, the added value of the fertilizer products is relatively low. The goal of this research team is to successfully manufacture a biodegradable seedling tray with cow dung to improve the economic value of cow dung and add to a growing area of research. The results of the study might meet and simplify the process of maize seedlings replanting mechanization and enhance the promotion and application of maize seedlings replanting technology.

However, many previous studies have shown that the adhesion of cow dung was poor and that the material is hydrophilic. As such, the key problem in the manufacturing of degradable seedling trays with cow dung is to make the cow dung retain a desired shape through bonding, and then ensure that the seedling tray meets the requirements of replanting strength after seedling cultivation. Current studies on manufacturing and related mechanisms of the degradable seedling tray in agricultural production has mainly focused on the mixed molding of degradable substances and adhesives. Some scholars made seedling trays through starch glue bonding with water-resistant paper, basing the methodology on the starch gelatinization principle (Li et al. 2014). A thin plastic waterresistant layer in the water-resistant paper is not conducive to the degradation of the seedling tray; therefore, this method is not environmentally friendly. Other scholars have manufactured seedling trays through hot-forming after mixing starch glue and shredded 
crops straw based on the same principle. However, in this process of production, it is necessary to add the starch glue with a mass ratio of approximately $10 \%$ to the shredded crop straw to meet the strength requirement of the seedling tray. Because of the relatively high cost of starch glue, this method is not as economical as the previous examples. On the other hand, there are a lot of lignin in the nature. The lignin can be made to flow if the temperature is raised above its glass transition point. Molecular chain segments become mobile when the temperature is higher than the glass transition temperature. At that time, the lignin becomes soft, sticky, and has adhesive power. The glass transition temperature of lignin will range from 72 to $193{ }^{\circ} \mathrm{C}$, depending on the relative molecular weight and moisture content (Lebo et al. 2002; Hatakeyama and Hatakeyama 2009; Sen et al. 2015).

Based on this background, in the present study, the glass transition temperature of lignin in cow dung was exceeded during pressurizing and heating of the cow dung. The forming mechanism of the degradable seedling tray was studied using the autologous lignin of cow dung. From a microscopic perspective, the scanning electron microscope (SEM) was used to verify the recombination of its physical structure, and the results provided a theoretical basis for the formation of biomass seedlings, as well as a new approach and solution for the functional utilization of cow dung.

\section{EXPERIMENTAL}

\section{Materials}

Cow dung was collected from Beingmate, an industrial dairy cattle breeding company in Anda City, Heilongjiang province, China, with the dry matter composition shown in Table 1.

Table 1. Dry Matter Composition of Cow Dung

\begin{tabular}{|c|c|}
\hline Index $^{*}$ & Content (\%) \\
\hline Lignin & 24.6 \\
\hline Cellulose & 22.0 \\
\hline Hemicellulose & 12.5 \\
\hline * The composition of cow dung was analysed followed Fukushima and Hatfield (2004) and Lin and \\
Dence (2012). \\
\hline
\end{tabular}

\section{Cow dung pretreatment}

Four cow dung samples were taken and placed in a dry, dark, and ventilated environment to reduce the moisture content (MC) until the $\mathrm{MC}$ in the four cow dung samples dropped to $17 \%, 20 \%, 23 \%$, and 26\%, respectively. The codes MC1, MC2, MC3, and MC4 were used to represent the four kinds of cow dung samples with different moisture contents hereafter. The dried cow dung was placed into an agitator (Ice City $\mathrm{BH}-$ 12.5, Harbin, China) and stirred at a speed of $20 \mathrm{r} / \mathrm{min}$ for $10 \mathrm{~min}$ until the cow dung had a looseness degree of $0.4 \mathrm{t} / \mathrm{m}^{3}$.

\section{Methods}

Molding experiment- Normal temperature compression molding (NTPM)

After treatment, $300 \mathrm{~g}$ of the cow dung was placed into the compression forming mold for the maize seedling tray (Produced by the authors' laboratory), which was then compressed by a press (YJ-1000; Xiangyang Machinery Factory, Zhejiang, China) at a 
pressure of $20 \mathrm{MPa}$. After compression, the mold was withdrawn once the pressure was maintained for $20 \mathrm{~s}$; then the seedling tray was dried at room temperature for $48 \mathrm{~h}$. The size of the maize seedling tray mold was $276.5 \mathrm{~mm} \times 42 \mathrm{~mm} \times 35 \mathrm{~mm}(\mathrm{~L} * \mathrm{~W} * \mathrm{H})$.

\section{Hot pressing molding (HPM)}

The induction coil of the electromagnetic induction heater (5-220; Haojiarun Electric Co., Ltd., Guangdong, China) was wrapped around the external surface of the mold material frame. Then, the output current of the electromagnetic induction heater was adjusted to heat the mold to $230{ }^{\circ} \mathrm{C}$ and a constant temperature was maintained. After forming, the steady-state temperature difference between the inner and outer surfaces of the seedling tray material were measured by heat flow thermal conductivity tester (DRXRL. Zhenhua Analytical Instrument Co., Ltd., Hunan, China). The temperature difference between the inner and outer surfaces of the $3.5 \mathrm{~mm}$ thick seedling tray was $\leq 35.43{ }^{\circ} \mathrm{C}$. From here, $300 \mathrm{~g}$ of the treated cow dung (MC of the complete molding material in the NTPM test) was placed into the compression-forming mold of the maize seedling tray, which was then compressed with a pressure of $20 \mathrm{kN}$. Once the temperature of the mold naturally fell to below $50{ }^{\circ} \mathrm{C}$, the tray was withdrawn, after compression and heat preservation for $20 \mathrm{~s}$.

\section{Seedling cultivation test}

The maize seeds (KW9F592; Kenfeng Seed, Heilongjiang, China) were soaked in warm water $\left(28^{\circ} \mathrm{C}\right.$ to $30^{\circ} \mathrm{C}$ ) for 2 to 3 days before sowing, and then they were removed to drain for 8 to $12 \mathrm{~h}$. The seeds were then allowed to sprout at a temperature between $20^{\circ} \mathrm{C}$ and $25^{\circ} \mathrm{C}$. The seeds were turned every $2 \mathrm{~h}$ to $3 \mathrm{~h}$ until the seeds' radicles were exposed. Then, the molded NTPM seedling tray and HPM seedling tray were used as described below. First, $2 \mathrm{~cm}$ of subsoil was placed in the hole, and seeds were sown after pregermination at each point. The surface was covered with a layer of topsoil until flush with the edge of seedling tray hole, and the seedlings were watered until completely soaked. The ambient temperature for culture of seeding was $25 \pm 2{ }^{\circ} \mathrm{C}$, the environment humidity was $45 \%$ to $65 \%$, and the cultivation time for seeding was $15 \mathrm{~d}$.

\section{Side wall expansion test of seedling tray}

The thickness of the sidewall of the seedling tray was measured with an electronic vernier caliper (202161, VOGEL, Germany). The thickness of the hole sidewall of each seedling tray was measured three times, and the average value was measured. Ten samples were taken for the same moisture content seedling tray. When the seedling tray after raising seedlings was measured, the sidewall of the seedling tray was peeled from the seedling soil and the measurement was carried out according to the above method.

\section{Measurement of the rupture strength of seedling tray}

The seedling tray molded after the NTPH and HPH were placed on the experimental platform of an electronic universal testing machine (WDW- 200 EIII; Jinan Times Test Gold Testing Machine Co., Ltd., Jinan, China), which conformed to the GB/T 16491 (2008). The sample tray was destroyed at a constant loading rate of $10 \mathrm{~mm} / \mathrm{min}$ through a three-point bending process with unrestrained support. The termination position was set as $6 \mathrm{~mm}$ at the closed-loop control, and the holding time was set as $10 \mathrm{~s}$. During the duration of the process, the load and deflection applied on the sample were measured to determine the bending strength, bending elastic modulus, and the relationship between bending stress 
and strain. The span $(L)$ and the position of the upper pressure head was adjusted to an accuracy of $0.5 \mathrm{~mm}$, and the $L$ value used in this experiment was $210 \mathrm{~mm}$. The upper pressure head was located in the middle of the support beam, and the cylindrical surface axis of the upper pressure head and the support beam was parallel. The test was completed in accordance with IOS 14125 (1998). The samples were symmetrically placed in the middle of the support beam, and the pressure head was preloaded on the sample surface. Then, the instruments were checked to ensure that the whole system was in a normal state. Afterwards, the test was started once the zero load and displacement was made. The same method was used to measure the seedling tray after the seedling cultivation.

\section{SEM scanning of the molding materials}

From a $1 \mathrm{~cm} \times 1 \mathrm{~cm}$ seedling tray surface sample, the stripping face of the sample was placed upward and pasted on to the sample table using double-sided tape. The tray was then placed on an ion-sputtering instrument (DII-29030SCTR; JEOL Ltd., Tokyo, Japan) for two, $30 \mathrm{~s}$ metal spraying treatments. The gold-sprayed sample was placed together with the sample mount under the scanning electron microscope (JCM-6000; JEOL Ltd., Tokyo, Japan) for observation. The acceleration voltage of the SEM was set at $15 \mathrm{kV}$.

\section{TG/DTA (Thermo-gravimetric /Differential Thermal Analyzer) test}

Thermogravimetric analyzer (HTG-1; Beijing Hengjiu Experimental Equipment Co., Ltd, Beijing, China) was used to detect and analyze biomass materials. The first step was to raise the furnace to expose the support rod (thermocouple assembly). Next, the experimental sample (HPM, $70 \mathrm{mg}$ ) was placed into the ceramic crucible $\left(\mathrm{Al}_{2} \mathrm{O}_{3}\right)$, placed on the thermocouple plate steadily, and the heating furnace body was lowered. Two empty alumina crucibles were placed on the support rod differential heating plate, and the position of the crucible was adjusted to the center of the sample position. The lid was placed on the stove. Then the sample was heated at a rate of $5{ }^{\circ} \mathrm{C} / \mathrm{min}$, allowing the temperature to rise to a final temperature set to $500{ }^{\circ} \mathrm{C}$. During the temperature measurement, the analysis software was turned on and the temperature changes were recorded in real time.

\section{XRD (X-ray Diffraction) test}

A milling and tablet pressing machine (769YP-15A; Xinnuo Instrument Group Co.Ltd, Shanghai, China) was used to grind HPM and NTPM samples. The diameter of the powder after grinding was about $40 \mu \mathrm{m}$. The powder was tested by X-ray diffractometer (D8 Advance; Bruker Daltonics, Germany), and the testing results were analyzed by JADE 6.5 software.

\section{FTIR (Fourier Transform Infrared Spectroscopy) test}

One gram of HPM sample was weighed according to the amount required for solid tableting, and a powder tableting machine was used to grind the tablet, respectively. The diameter of the powder after grinding was about $40 \mu \mathrm{m}$. Then the tablet pressing function of the machine was started, with an increase of the pressure to $37 \mathrm{MPa}$. After waiting for 30 seconds, the tablet was taken out carefully. The same method was used to make compressed tablets of NTPM samples. The compressed tablets were analyzed using FTIR (IRTracer-100; Shimadzu, Japan). 


\section{RESULTS AND DISCUSSIONS}

\section{Molding Experiment}

\section{Results and discussions of normal temperature compression molding experiment}

Figure 1 shows the shape of the NTPM seedling tray made from cow dung (MC1, $\mathrm{MC}$, MC3, and MC4) with different moisture contents after the RT drying. From a top view of the MC1 cold-pressed seedling tray, it was visible that the upper edge of the outer wall and the hole partition were loose (Fig. A1). The side view (Fig. A2) shows that the outer wall of the seedling tray was incomplete, and the bottom of the seedling tray (with a thickness of $8.3 \pm 1.2 \mathrm{~mm}$ ) had serious material accumulation and a multilayer fracture on the side face. At the beginning of the seedling tray molding, the porosity was reduced, and the materials were stacked at the bottom of the mold frame due to compression. The pressure within the mold rose with the increasing pressure applied on the mold. The materials that accumulated at the bottom were able to produce a component force outward along the bottom of the mold due to the compression. When the flow stress of this component was greater than that of the material, the materials flowed from the bottom to fill the gap between the inner wall of the mold material box and the seedling tray hole mold, so as to form the side wall of the seedling tray.

In contrast, $\mathrm{MC}$ differences in the raw materials might affect the molding integrity of the seedling tray, as well as the fluidity of the material on the mold (Tumuluru 2018). The rheological stress of the materials increased with the decrease of the MC through a graded trend relationship. After the compression molding of the MC1 material at the bottom of the seedling tray, the higher rheological stress of the material made it difficult to fill the side wall of the material frame after its accumulation at the bottom. As such, it was unable to form the side wall of the seedling tray. Moreover, stratification of the density occurred at the bottom of the thick seedling tray. This was caused by the attenuation of the pressure conduction, thereby resulting in a multilayer fracture. As shown in the top view and side view (Figs. 5B1 and 5B2, respectively) of the cold-pressed seedling tray of the MC2 material, there was no fracture on the side wall of the seedling tray, the bottom thickness of the seedling tray was $6.4 \pm 0.3 \mathrm{~mm}$, and upper edge was not completely formed at a depth of $5.2 \pm 2.1 \mathrm{~mm}$. The materials were filled from the bottom to the side wall of the material frame after compression, and the upward flowing materials continued to pile up after reaching contact with the lower surface of the male mold to generate pressure and shape the top of the seedling tray. The increase of material flow distance resulted in an increase in contact area between the material and the inner wall of the material frame, thus increasing the flow resistance. Due to the poor liquidity of the MC2 material, the upper materials on the side wall could not flow to the state that it could contact the lower surface of the male mold, and as a result, could not complete the compression molding. In contrast, the MC3 and MC4 materials were fully molded after being compressed at room temperature, with the bottom thickness of the seedling tray for MC3 and MC4 at 4.6 \pm 0.2 $\mathrm{mm}$ and $5.1 \pm 0.2 \mathrm{~mm}$, respectively.

As shown in Fig. 5C1, the upper edge of the $\mathrm{MC} 3$ seedling tray was relatively neat, and the outer surface was smooth (Fig. 5C2). As shown in Fig. 5D1, the outer surface of the MC4 seedling tray was not smooth and there were overflow materials on the edge of the seedling tray. The forming mold was semi-closed, with a $0.2 \mathrm{~mm}$ clearance between the upper surface of the material frame and the lower surface of the male mold. The materials flowed upwards along the inner surface of the material frame in the compression process and increased the pressure within the mold after contact with the lower surface of 
the male mold. When compared with the MC4 material, the MC3 material had better mobility, and the inner and outer pressure required by the material to move through a similar-sized hole was also smaller (Street et al. 1996). Accordingly, there was material overflow at the upper edge of the seedling tray after cold press molding of the MC4 material. The prerequisites needed to meet the requirements of raising the seedling was the integrity of the seedling tray. The seedling tray could be fully formed when the moisture contents of the materials in the above NTPM test results were $23 \%$ and $26 \%$, respectively. Therefore, MC3 and MC4 materials were selected for the HPM test.
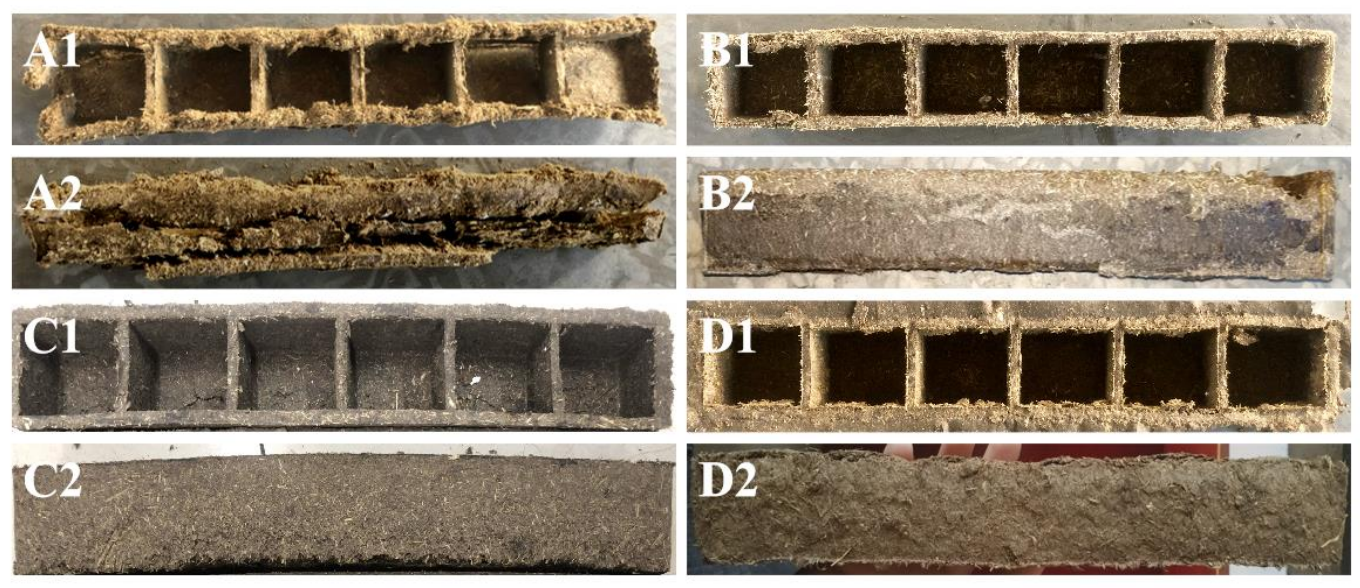

Fig. 1. Cold-pressed seedling trays: $A, B, C$, and $D$ are the cold-pressed seedling tray of MC1, MC2, MC3, and MC4 materials, respectively; the 1 indicates the top view of the seedling tray, and 2 is the side view of the seedling tray

\section{Results and discussions of the hot compression molding experiment}

The shape of the HPM seedling tray dried at room temperature is shown in Fig. 2, of which Fig. 6E showcases the seedling tray manufactured with the MC3 material. As seen from E1 and E2, the upper edges of the seedling tray were neat and the outer wall was smooth. Figure $6 \mathrm{~F}$ shows the seedling tray manufactured with the MC4 material, where there was material overflow on the edge of the seedling tray in spite of the smooth outer wall. This was also caused by the good fluidity of the materials.
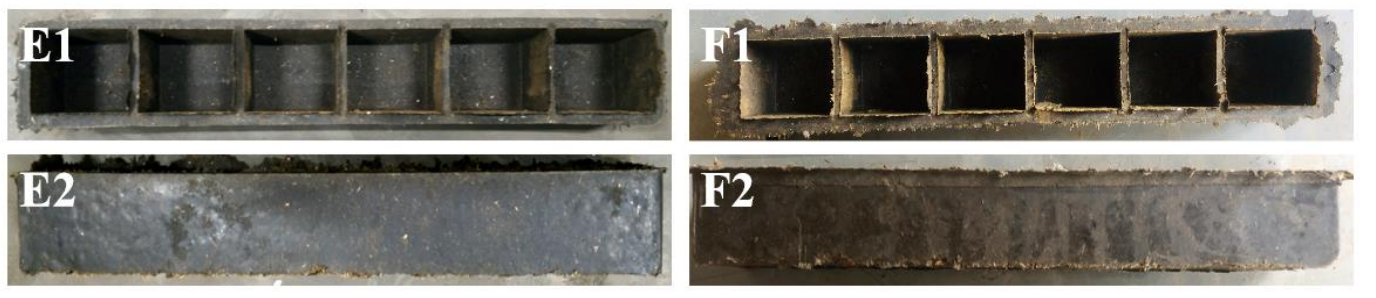

Fig. 2. HPM seedling tray: where E and F represent the HPM trays of materials MC3 and MC4, respectively; here 1 is the top view of the seedling tray, and 2 is the side view of the seedling tray

\section{Seedling cultivation results}

Figure 3 (C1, D1, E1, and F1) shows the completely soaked state of the seedling trays after NTPM and HPM with the use of the MC3 and MC4 materials. The soil was separated from the inner wall of the seedling tray in Figs. 7C2 and 7D2 after $15 \mathrm{~d}$ of 
seedling cultivation, and the side wall of the seedling tray was significantly expanded $(\mathrm{P}<$ 0.05). In Fig. 7C2, fractures can be seen at the fourth- and fifth-hole joints from the left, and the seedling tray was bent and deformed as a whole. Meanwhile, fractures could be seen at all hole joints in Fig. 7D2. The seedling nursery soil and the inner wall of the seedling tray were not separated in Figs. 7E2 and 7F2, of which the side wall in E2 had no obvious expansion, but where a slight expansion of the side wall and increased width of the seedling tray were seen in F2. Additionally, there were no fractures in the seedling trays shown in Figs. 7E2 and 7F2.
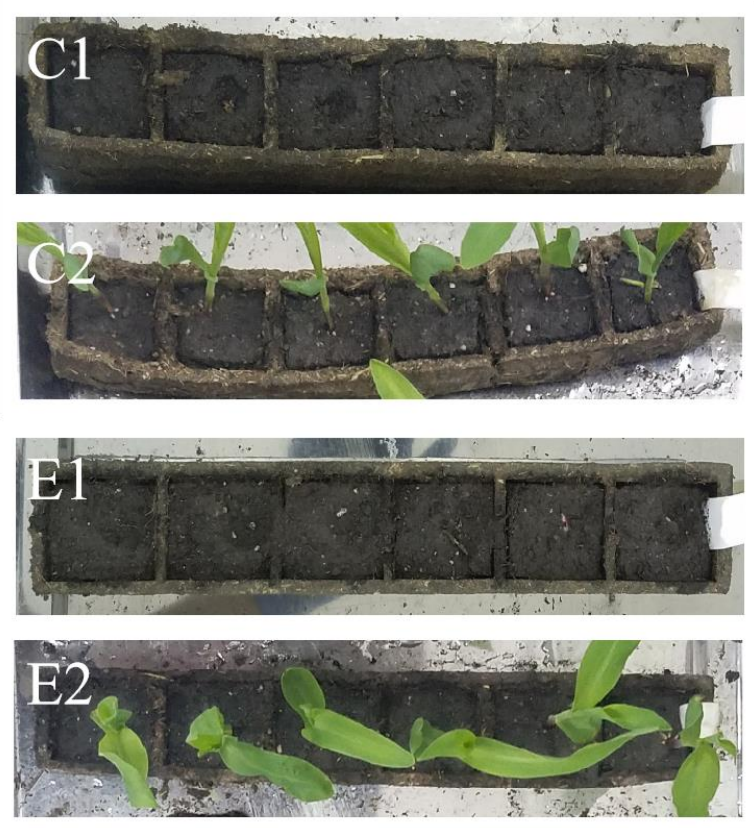
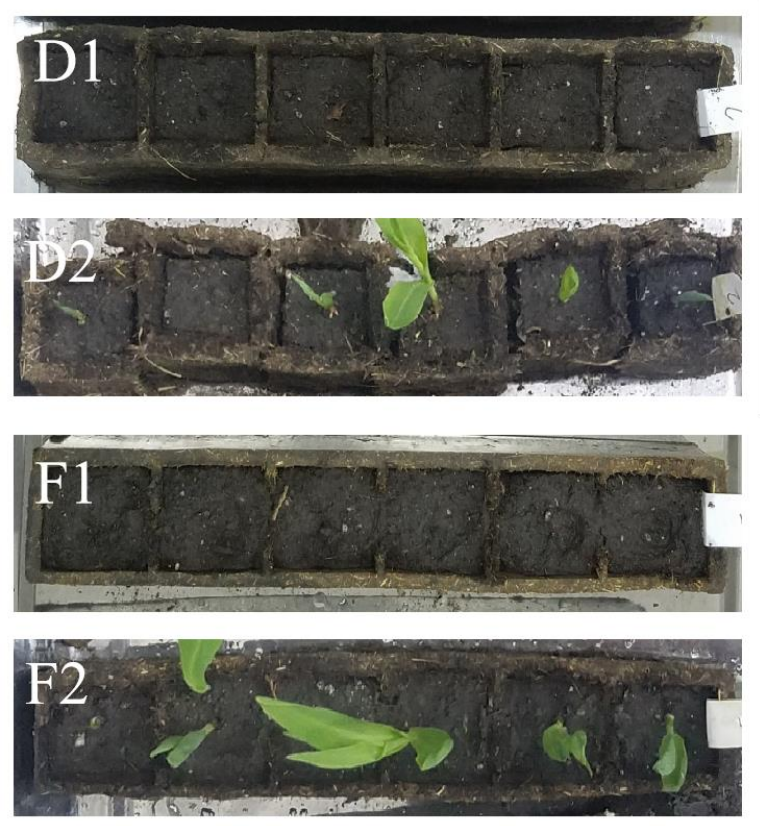

Fig. 3. $C$ and $D$ represent the NTPM seedling trays using $M C 23 \%$ and $M C 26 \%$ materials, $E$ and F show the HPM seedling trays manufactured with MC $23 \%$ and MC $26 \%$ materials, 1 is the shape of the seedling tray after sowing and watering, and 2 is the shape of the seedling tray after 15 days of seedling cultivation

Table 2 below shows the dimensional change of the side wall before and after seedling cultivation. As shown in the table, the expansion rate hierarchy was $\mathrm{E}<\mathrm{F}<\mathrm{C}<$ $\mathrm{D}$ after seedling cultivation, and the soil for the seedling cultivation showed no expansion when exposed to water. However, a large expansion rate could be seen in the $C$ and $D$ seedling trays.

The different expansion rates led to a serious expansion of the seedling tray on the side wall, thereby causing its separation from the seedling soil after watering. Meanwhile, due to the different stress directions generated by the expanding side wall of the seedling tray, as well as the hole partition in the expansion process of the seedling tray, the stress rupture occurred at the joint between the side wall of the seedling tray and the hole partition, as shown in Figs. 7C2 and 7D2. In Figs. 7C2 and 7D2, the seedling trays were all fractured after the seedling cultivation; therefore, only the seedling trays in Figs. 7E2 and 7F2 were selected to detect the seedling tray strength after the seedling cultivation. 
Table 2. Dimensional Changes in the Side Wall of Seedling trays Before and After Seedling Cultivation

\begin{tabular}{|c|c|c|c|c|}
\hline & $\mathrm{C}^{\mathrm{a}}$ & $D^{b}$ & $\mathrm{E}^{\mathrm{c}}$ & $F^{d}$ \\
\hline $\begin{array}{c}\text { Wall Thickness Before } \\
\text { Seedling Cultivation (mm) }\end{array}$ & $4.2 \pm 0.2 \mathrm{a}$ & $4.8 \pm 0.3 a$ & $3.8 \pm 0.1 \mathrm{a}$ & $4.1 \pm 0.1 \mathrm{a}$ \\
\hline $\begin{array}{l}\text { Wall Thickness } 15 \mathrm{~d} \text { After } \\
\text { Seedling Cultivation (mm) }\end{array}$ & $6.6 \pm 0.3 b$ & $8.9 \pm 0.4 b$ & $4.4 \pm 0.2 \mathrm{a}$ & $5.2 \pm 0.2 \mathrm{a}$ \\
\hline Expansion Rate (\%) & $57.2 \pm 0.3$ & $85.5 \pm 3.3$ & $15.8 \pm 2.2$ & $26.8 \pm 4.2$ \\
\hline
\end{tabular}

Measurement results and discussions with universal testing machine

The bending strength test results of the NTPM and HPM seedling trays manufactured with MC3 and MC4 materials are shown in Figs. 4 and 5. It can be seen from the figure that, for the materials with the same moisture content, the HPM seedling trays showed better toughness and less of a strength difference than the NTPM seedling trays. After the HPM seedling cultivation, the bending strength of the MC3 molded seedling tray was higher than that of the MC4 molded seedling tray.

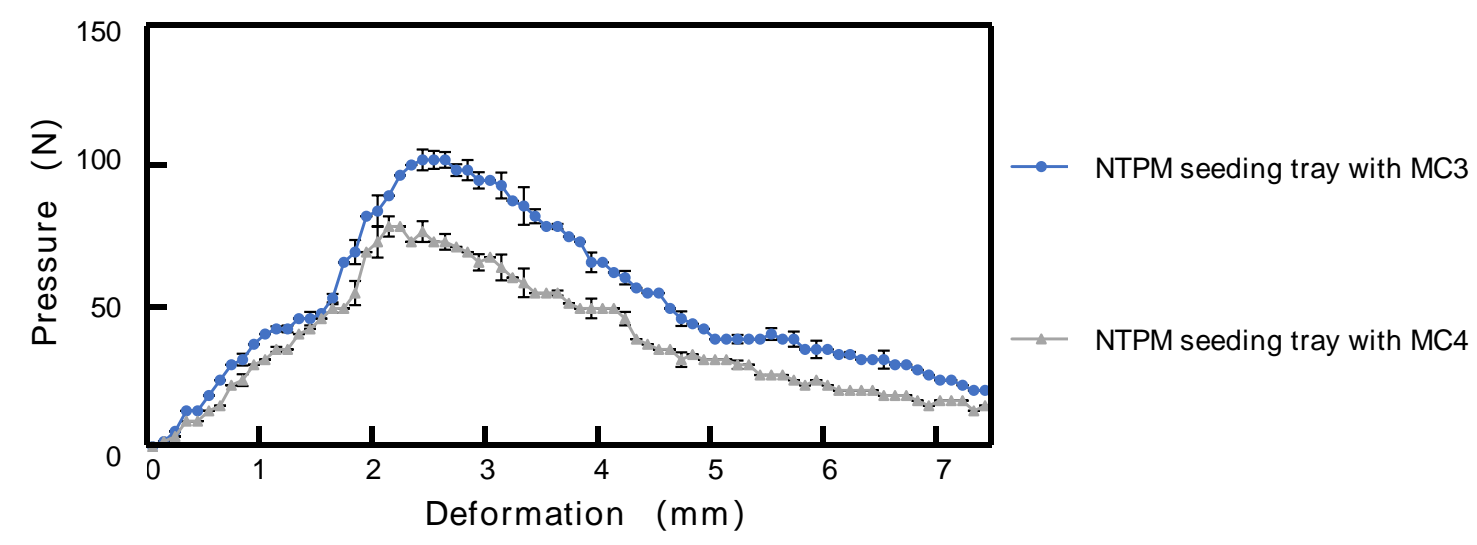

Fig. 4. Bending strength test results of the NTPM seedling trays with MC3 and MC4 materials

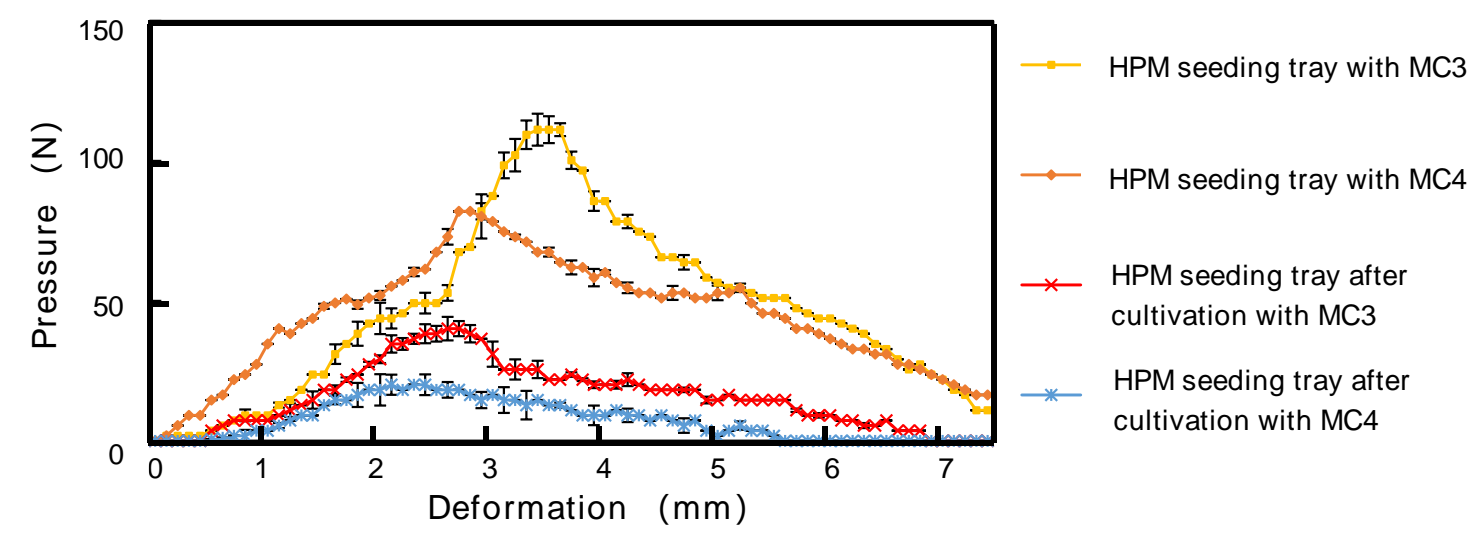

Fig. 5. Bending strength test results of the HPM seedling trays with MC3 and MC4 materials 
Table 3 shows the bending strength and elastic deformation of the seedling trays, in which the bending strength of the NTPM seedling tray with material MC3 before seedling cultivation was $101.6 \mathrm{~N}$, while the same value of the NTPM seedling tray with material MC4 before seedling cultivation was $79.6 \mathrm{~N}$. The bending strength of the HPM seedling tray with material MC3 was $111.3 \mathrm{~N}$ before seedling cultivation, and $41.2 \mathrm{~N}$ after cultivation, resulting in the strength decrease of $63.0 \%$. Similarly, the bending strength of the HPM seedling tray with material MC4 was $82.6 \mathrm{~N}$ before cultivation and $20.1 \mathrm{~N}$ after cultivation, with a strength decrease of $75.7 \%$. The bending strength and elastic deformation of the material MC3 seedling tray before and after seedling cultivation were greater than that of the material MC4 seedling tray.

Table 3. Bending Strength and Elastic Deformation of Seedling trays

\begin{tabular}{|c|c|c|c|c|c|}
\hline \multirow{2}{*}{$\begin{array}{c}\text { MC of Material } \\
(\%)\end{array}$} & \multirow{2}{*}{$\begin{array}{l}\text { Molding } \\
\text { Mode }\end{array}$} & \multicolumn{2}{|c|}{ Failure Load $(\mathrm{N})$} & \multicolumn{2}{|c|}{ Elastic Deformation (mm) } \\
\hline & & $\begin{array}{c}\text { Before } \\
\text { Cultivation }\end{array}$ & $\begin{array}{c}\text { After } \\
\text { Cultivation }\end{array}$ & $\begin{array}{c}\text { Before } \\
\text { Cultivation }\end{array}$ & $\begin{array}{c}\text { After } \\
\text { Cultivation }\end{array}$ \\
\hline \multirow{2}{*}{23} & NTPM & $101.6 \pm 3.1 \mathrm{a}$ & & $2.7 \pm 0.1 \mathrm{a}$ & \\
\hline & HPM & $111.3 \pm 1.7 \mathrm{a}$ & $41.2 \pm 2.9$ & $3.5 \pm 0.1 b$ & $2.7 \pm 0.1$ \\
\hline \multirow{2}{*}{26} & NTPM & $79.6 \pm 2.9 \mathrm{a}$ & & $2.2 \pm 0.1 \mathrm{a}$ & \\
\hline & HPM & $82.6 \pm 1.8 \mathrm{a}$ & $20.1 \pm 2.7$ & $2.8 \pm 0.1 b$ & $2.3 \pm 0.2$ \\
\hline
\end{tabular}

a,b. Samples within the same $\mathrm{MC}$ and the same column not sharing a common letter are significantly different at $\mathrm{P}<0.05$

The lignin in cow dung was softened with the temperature rise of the mold in the process of HPM. The material was also able to bond with surrounding particles after precipitation under the action of internal stress, thus providing a better integrity for the seedling tray. The strength of lignin itself was not high after solidification (Xiao et al. 2013); meanwhile, the mechanical strength of the biomass materials after compression was mainly attributable to the solid bridging between the biomass particles and the mechanical inlay (Rumpf 1970). Therefore, the strength of the HPM seedling tray was not improved significantly $(\mathrm{P}>0.05)$ when compared with that of the NTPM seedling tray under the same conditions of material. The viscoelasticity of lignin (Salmén 1984) could have made the HPM seedling tray compacted by materials with the same moisture content, which led to more elastic deformation than the NTPM tray. In the compression molding test mentioned above, all the MC4 materials had the phenomenon of overflowing from the exhaust gap above the grinding tool after the compression. This is because the fluidity of the biomass material increases with the increase of the water content, so the MC4 has higher fluidity. The material will overflow from the gap of the mold when a non-completely sealed mold was used to compress the material. This resulted in the internal pressure of the mold during compression of the MC4 material to be less than that of the compressed MC3 material due to the decreased material density (Rumpf and Gupte 1971). At the same time, while the gaps between the materials are filled with lignin during the compression process, it will also be filled with moisture in the materials. The moisture in the gap of material will hinder the filling of the gap with lignin, thereby reducing the binding effect of lignin on the stem fiber. Therefore, the seedling tray manufactured with MC3 through compression molding showed the higher bending strength. 
The bending strength of the HPM and NTPM seedling trays manufactured with the materials with the same moisture content showed little difference. Additionally, the fracture occurred in the seedling cultivation by using the NTPM seedling tray. Accordingly, it was determined that the strength of the NTPM and HPM seedling trays was mainly due to the solid bridging between particles and the mechanical setting. Lignin was migrated under the effect of internal stress in the HPM, thereby bonding the surrounding particles and enclosing the mechanical setting structure among some particles. Due to the hydrophobic nature of lignin (Sammond et al. 2014), the mechanical setting structure coated by lignin in water was not damaged by the water; therefore, the seedling tray maintained a certain strength when exposed to water.

\section{SEM Results and Discussions}

Figure 6 shows the SEM images of the seedling tray, in which the fibrous materials in the figures are the stem fiber in the cow dung that was not fully digested by the cow. These materials were mainly composed of lignin and cellulose. The irregularly shaped parts marked in the figure are impurities in the cow dung, which are mainly composed of cow gastrointestinal secretions and undigested lignin (Whitehead and Raistrick 1993). Figures 6A and 6B are the SEM images of the NTPM seedling tray samples, displaying how a large amount of stem fibers in cow dung were stacked and embedded together. In addition, it was clear that the straw stalk gap of the MC3 materials was smaller than that of the MC4 materials after molding and drying. The SEM images of the NTPM seedling tray samples are shown in Figs. 6C and 6D, in which most of the stalk fiber gaps were filled and adhered by the lignin, and most of the stem fiber laminated inlay structures were enclosed by lignin. The MC4 material (Fig. 6D) also appeared after the HPM lignin-filled cracks and adhesion between the cascade stem fiber phenomenon. Though a portion of gaps were not filled and adhered, the stem fiber laminated inlay structure was not largely covered by the lignin.

The gaps between cellulose shown in the SEM imaging figures were generated by the internal stress and moisture in the materials. Because of the uneven volume changes occurred in the microstructure of the materials, and the internal residual stress that still existed during the compression process, the materials produced gaps after molding when the external load disappeared. After the lignin is squeezed out of the cellulose gap, the lignin adhered to the adjacent fibers and formed into a new whole. After the external load disappeared, most of the internal stress was offset by the bond force of the lignin; therefore, both the expansion rate and void rate of the HPM tray after molding were lower than those of the NYPM tray. The moisture in the material was involved in filling the gaps in the process of compression. This moisture eventually evaporated to create material gaps after drying. The higher moisture content in the material could result in a larger gap after drying; therefore, this explained why the gaps between stalk fibers in Figs. 6B and 6D might have been larger than those in Figs. 6A and 6C. The mechanical setting force of the materials was generated by the stacked and extruded materials, such that a larger material gap resulted in a smaller mechanical inlaying force. In the universal experiment machine test above, the bending strength of the seedling tray molded with material MC3 was greater than that of the seedling tray molded with material MC4, which was also a result of this reasoning.

The flow of lignin inside the material could be divided into two stages. In the first stage, the lignin in stem fibers flowed and separated out under the internal pressure after reaching the softening temperature, so as to fill the gaps between adjacent stem fibers. Accordingly, the higher filling rate of lignin in the gaps between stem fibers could bring 
about better integrity of the seedling tray, a better adhesion effect, as well as a stronger toughness after molding. In the second stage, as the temperature and lignin fluidity increased, the lignin in the gaps overflowed, and covered and enclosed more adjacent stem fibers. This formed the lignin layer outside the stem fiber laminated inlay structure. In the whole course, because the liquidity of water was higher than that of lignin, the moisture inside the biomaterials gave priority to filling the adjacent stem fiber gaps after the internal air was discharged through compression, which affected the lignin adhesion to stem fibers and films. As a result, the higher moisture content could lower the adhesion and film forming effect of lignin while improving the flow rate of materials. Yan et al. (2009) studied the relationship between moisture content and the strength of biomass after molding. The results show that too high or too low moisture content will reduce the forming rate of biomass, and a proper moisture content is conducive to improving the compactness of the material. Those findings were the same as the results of this article. This article makes further observation from the microscopic perspective, and the effect of moisture content on the internal changes of the biomass material after forming was analyzed.
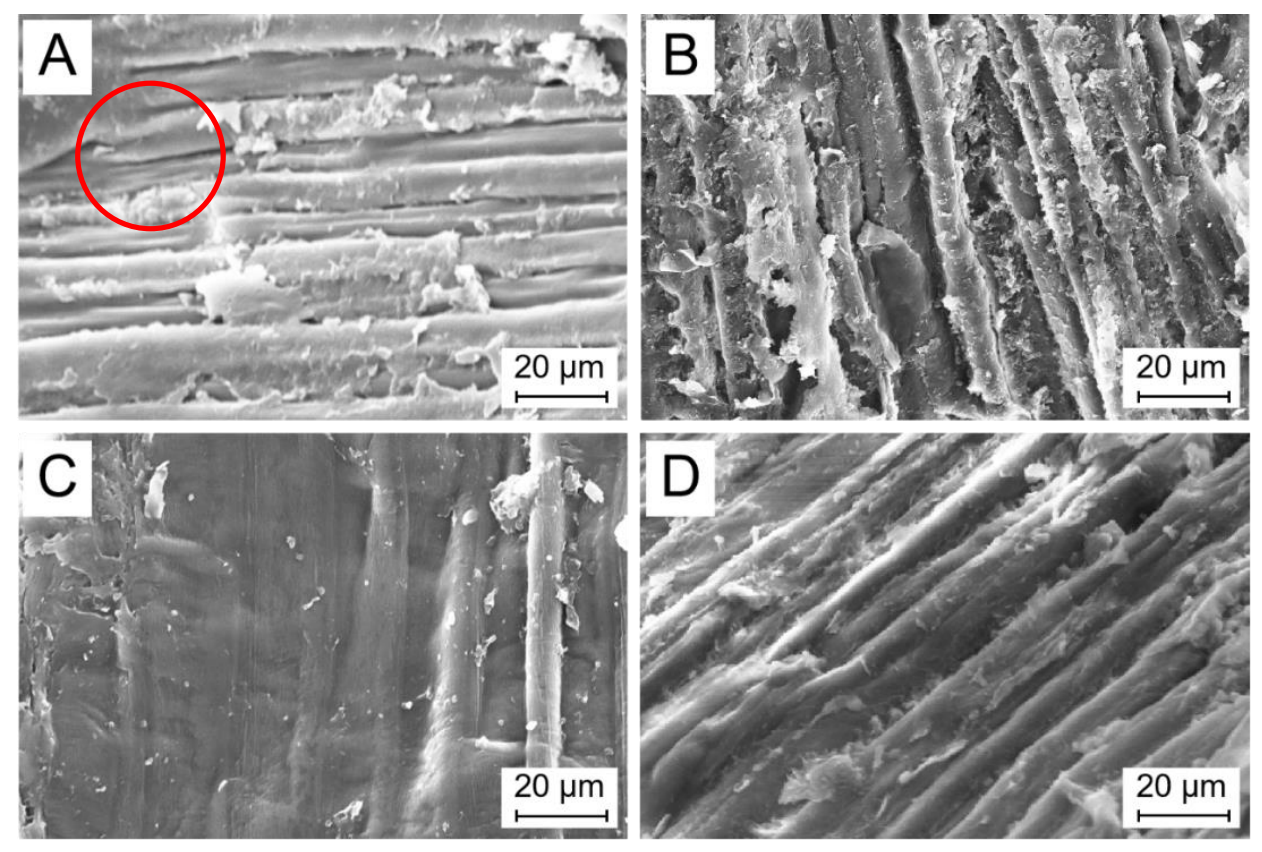

Fig. 6. SEM images of seedling tray: A, B, C, and D are the NTPM of the MC3 material, NTPM of the M4 material, HPM of the M3 material, and HPM of the M4 material, respectively

Figure 7 shows the SEM images of the seedling tray after seedling cultivation, of which Figs. 7E, 7F, 7G, and 7H are the SEM images of the NTPM with MC3 material, NTPM with MC4 material, HPM with MC3 material, and HPM with MC4 material, respectively. As shown in Fig. 7E, the laminated inlay structure of stem fibers was seriously damaged, and the laminated inlay part of the stem was less than one-sixth of the whole structure. Figure $7 \mathrm{~F}$ shows that the laminated inlay structure was completely destroyed, and the stalk fibers were scattered and fluffy. After seedling cultivation in the tray with MC3 material, the laminated inlay structure of the stem fibers was clearly observed using SEM (Fig. 7G), and a small amount of the laminated inlay structure was destroyed. In Fig. $7 \mathrm{H}$, the laminated inlay structure of the stem layer was seriously damaged by water, and a large area of the fracture can be seen in the stem fibers. 


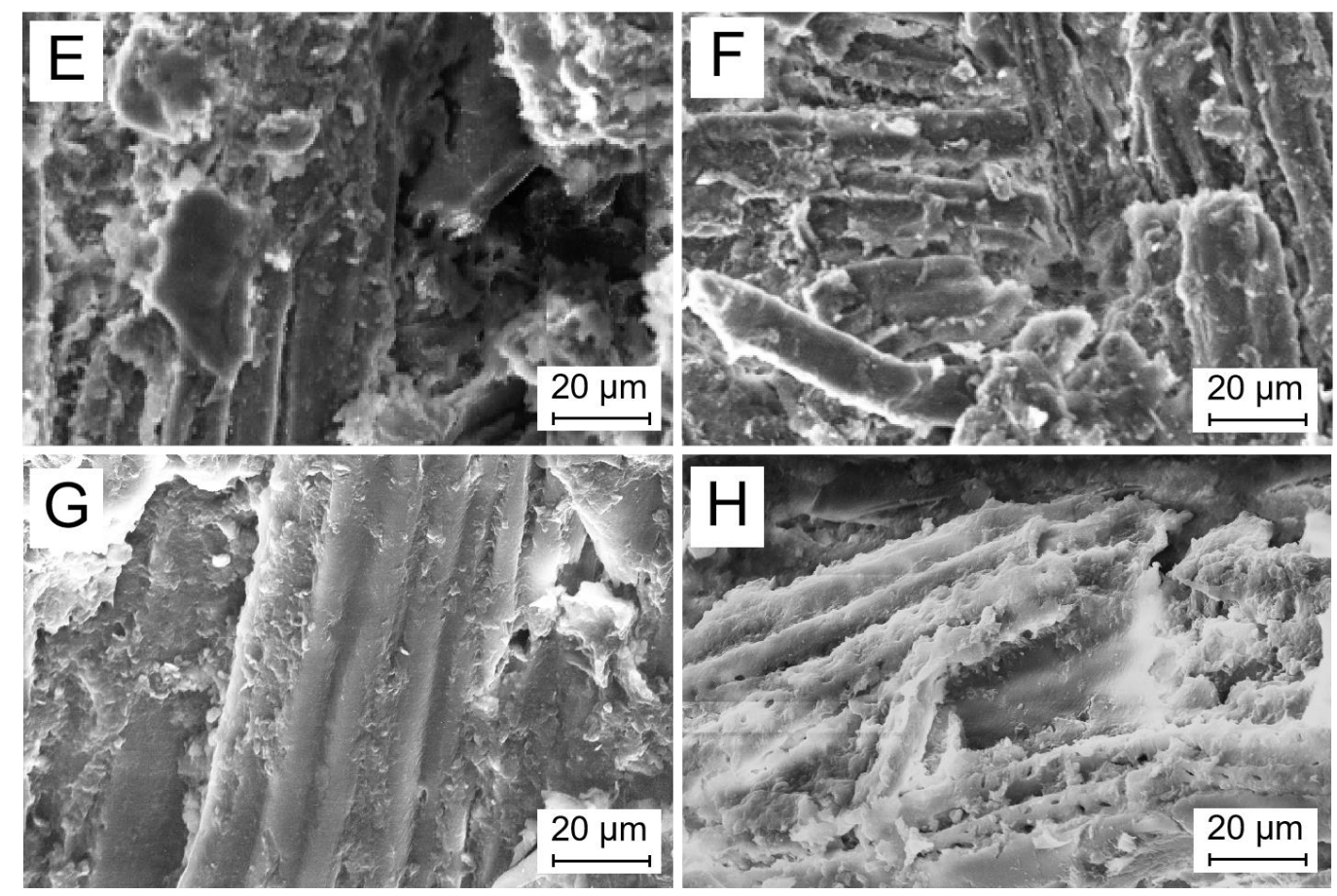

Fig. 7. SEM images of the seedling trays after seedling cultivation: $A, B, C$, and $D$ indicate the NTPM of the MC3 material, NTPM of the M4 material, HPM of the M3 material, and HPM of the M4 material, respectively

The soil moisture content during seedling cultivation was relatively high. Water flowed slowly from inside to the outside along the gaps between the stalk fibers in the NTPM seedling tray when exposed to water under the action of molecular adhesion and cohesion, and the larger gap could increase the penetration rate of water. The NTPM seedling tray with MC3 material was less damaged than that of the MC4 material due to its relatively small gap between the stalk fibers and slow infiltration process. The swelling property of cellulose makes it expand after water absorption (Espert et al. 2004); therefore, the water infiltration process causes cellulose expansion in the seedling tray, damaging the mechanical setting force. Lignin adhered to most of the cauline fibers of the HPM seedling tray; moreover, the stress intersection generated between the side wall of the seedling tray and the hole partition resulted in fractures when the seedling tray expanded. In terms of the HPM seedling tray, the lignin did not evaporate along with the water after drying and adhered to most of the stem fibers, and the filling of lignin in the gaps hindered the process of water capillary permeability (Maximova et al. 2001). The laminated inlay structure of the HPM seedling tray with MC3 material was heavily wrapped by lignin, which isolated the cellulose from water, thus preventing it from swelling, and protecting the stem laminated inlay structure from damage. The laminating inlay structure within the HPM seedling tray manufactured with MC4 material was not largely wrapped. As such, the lignin adhesion between adjacent stem fibers slowed down the water penetration, but did not completely isolate water-cellulose contact, such that the seedling tray swelled after being moistened. Simultaneously, some water infiltrated through the gaps, but was not completely filled, which caused stem fibers to crack after internal swelling, and reduced the strength of the seedling tray. This study verified the above speculation about the strength of the seedling tray. 
In summary, the forming mechanism of cow dung biomass in the process of compression molding was sorted out as follows: first, the stem fibers in the materials were compressed together to form a laminated inlay structure, and the mechanical setting force generated by the laminated stem fibers was the main source of the seedling trays own strength. In the research of Sun (2009), the physical form of biomass material also has three processes: looseness, compaction, and solidification during the compression process. The deformation process of the material includes plastic deformation and viscous deformation. Then, the increase of the mold temperature made the lignin inside reach its softening temperature, which formed a new hole through bonding with the adjacent stem fibers after precipitation under the action of internal stress. From here, the lignin liquidity ascended and adhered more adjacent stem fibers as the liquidation of lignin was intensified. Simultaneously, a lignin layer was formed outside the stem fibers' laminated inlay structure. Lastly, the seedling tray was formed when the temperature of the material was lower than the lignin glass transition temperature. Chen (2007) and Bai et al. (2008) used crushed crop stalks as raw material and mixed them with starch glue to prepare seedling bowls by heating and compression. In the experiment, the molding pressure, molding temperature, and binder mass ratio were used as influencing factors to study their effects on the performance of seedling bowls. In the test of the influence of molding temperature on the strength of seedling bowls, the lignin in the straw was softened under heating and acts as a binder during molding. However, the test temperature was $100{ }^{\circ} \mathrm{C}$, and the lignin was not completely softened. So in their research, the bonding of seedling trays mainly based on the gelatinization of starch glue rather than the bonding of lignin. Based on the above results, it was confirmed that the seedling tray manufactured by this experimental method had a certain water resistance and therefore could still meet the replanting intensity of seedlings after the maize seedling cultivation cycle.

\section{TG/DTA Results and Discussions}

Figure 8 presents the TGA plot of NTPM sample collected by the thermosgravimetric analyzer. The $\mathrm{x}$-axis is the heating temperature of the sample, TE. In addition, the $y$-axis is the mass lost by the sample, TG. In the figure, $T_{\mathrm{e}}$ stands for $T(\exp )$, which is the starting temperature of the epitaxy. $T_{\mathrm{i}}$ is the temperature at which the weight loss starts, at which the thermogravimetric curve begins to deviate from the baseline. $T_{\mathrm{c}}$ is the termination temperature of the extension in the weight loss curve. It is the temperature at the intersection of the tangent to the maximum rate of change point of the weight loss descending line and the maximum (final) weight loss line. \% is the percentage of the sample mass reduced in the corresponding temperature range. $\mathrm{d} W$ is the change rate of the test sample weight with respect to the temperature TE at the programmed temperature. It can be seen from Fig. 8 that there were three descending steps in the entire quality curve. In the first descending step, $T_{\mathrm{e}}=98.78{ }^{\circ} \mathrm{C}, T_{\mathrm{i}}=100.95{ }^{\circ} \mathrm{C}, T_{\mathrm{c}}=101.75{ }^{\circ} \mathrm{C}, \%=-2.85, \mathrm{~d} W=-2.00$. In the second descending step, $T_{\mathrm{e}}=250.54{ }^{\circ} \mathrm{C}, T_{\mathrm{i}}=265.71{ }^{\circ} \mathrm{C}, T_{\mathrm{c}}=268.99{ }^{\circ} \mathrm{C}, \%=-22.97$, $\mathrm{d} W=-16.08$. In the third descending step, $T_{\mathrm{e}}=482.81^{\circ} \mathrm{C}, T_{\mathrm{i}}=482.87{ }^{\circ} \mathrm{C}, T_{\mathrm{c}}=482.36{ }^{\circ} \mathrm{C}, \%=-$ $19.55, \mathrm{~d} W=-13.68$. The red line at $230{ }^{\circ} \mathrm{C}$ in Fig. 8 was marked by the author and indicates the heating temperature of the biomass material when making seedling trays. Figure 9 is the DTA image of NTPM sample collected by the thermogravimetric analyzer. 


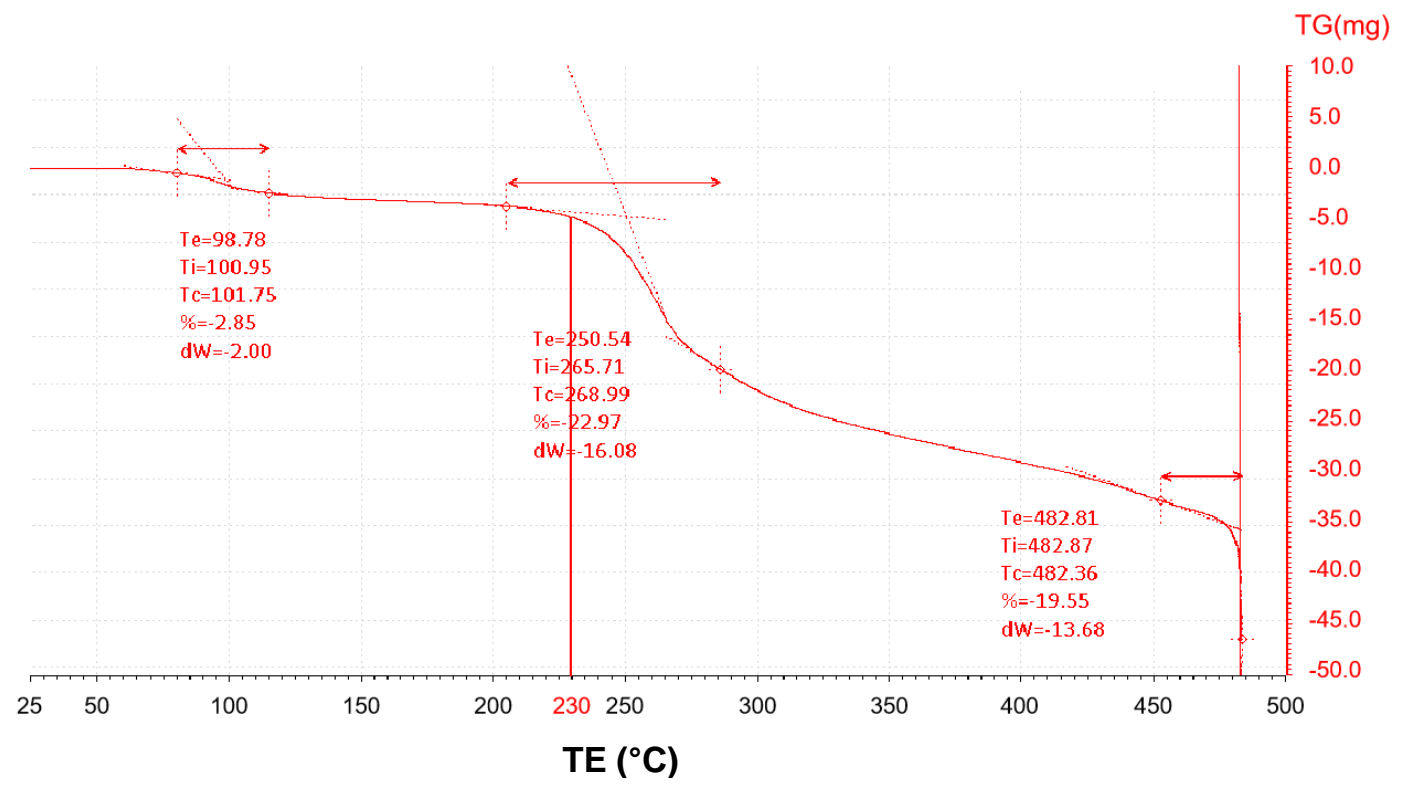

Fig. 8. TGA image of NTPM sample

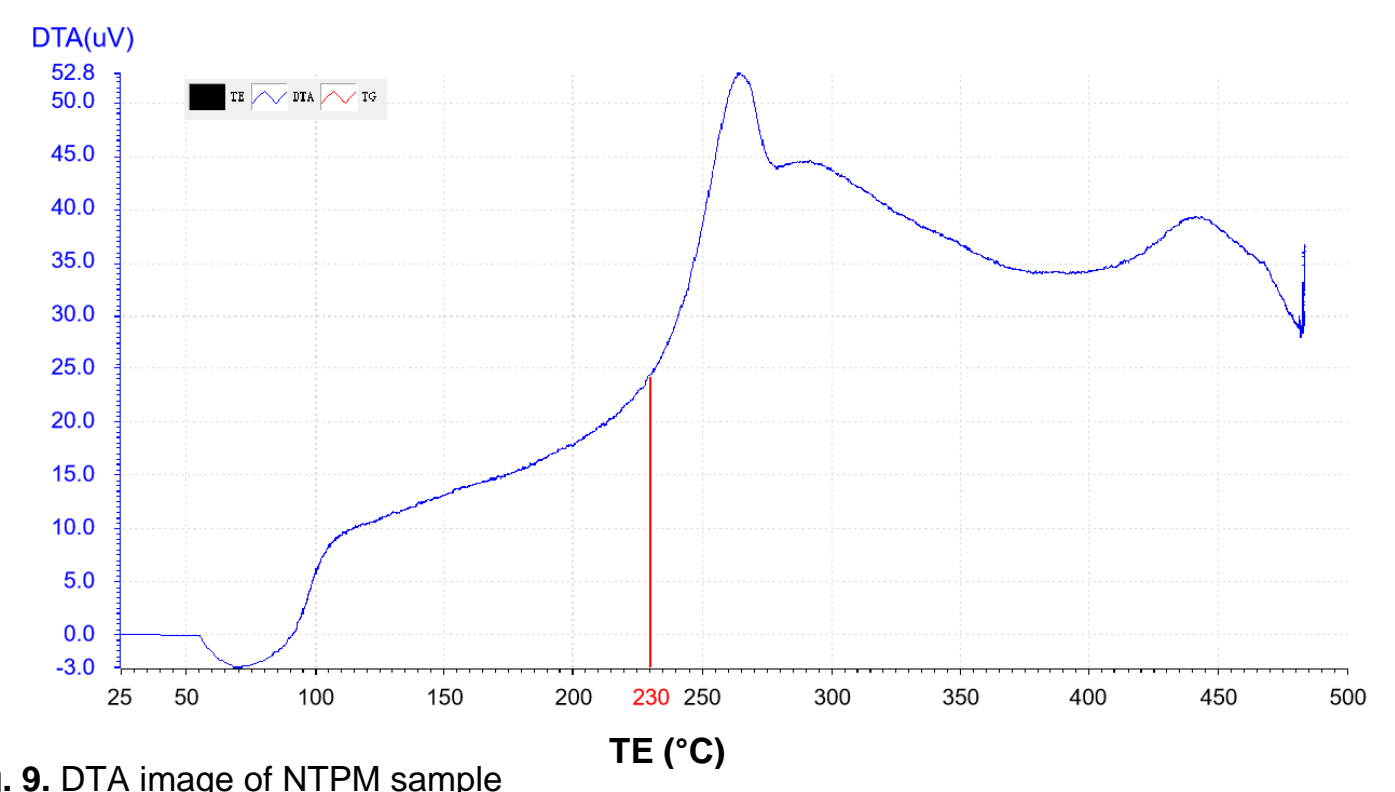

Fig. 9. DTA image of NTPM sample

It can be seen from Fig. 8 that in the descending step of the first curve at $98.78{ }^{\circ} \mathrm{C}$ to $101.75^{\circ} \mathrm{C}$, the reduced mass of the sample was $2.85 \%$ of the total mass, and the reduced mass in this temperature range was mainly the moisture inside the sample. In this temperature range, the DTA curve of Fig. 9 shows a descending peak, which indicates that the material in this temperature range absorbed heat, and further explains that the reduced sample mass in this temperature range was moisture. In the descending step of the curve in the second segment of Fig. $8\left(250.54{ }^{\circ} \mathrm{C}\right.$ to $\left.268.99{ }^{\circ} \mathrm{C}\right)$, the mass reduction of the sample was $23.0 \%$ of the total mass, and the initial temperature of the mass reduction was $250.54{ }^{\circ} \mathrm{C}$. A rising exothermic peak appears in the corresponding temperature range of the DTA curve, which is the pyrolysis temperature of lignin. In this paper, the biomass preparation temperature was $230{ }^{\circ} \mathrm{C}$, but there was no obvious quality degradation at $230{ }^{\circ} \mathrm{C}$ in Fig. 8. 
The lignin did not undergo thermal decomposition at this temperature, indicating that the preparation temperature of the biomass seedling tray in this paper did not decompose after the lignin was fluidized, so the temperature was reasonable. The specific molecular bond breakage and internal composition changes will be explained in the XRD and FTIR test results later. Combined with the curve in Fig. 9, the descending step of the curve in the third section of Fig. 8 corresponds to the carbonization process of biomass materials at high temperatures.

\section{XRD Results and Discussion}

Figure 10 shows the XRD images of NTPM and HPM samples. The red line in the figure is the diffraction result of HPM sample, and the black line is the diffraction result of NTPM sample. The abscissa represents the $2 \theta$ angle, which is the angle scanned by the diffraction spectrometer, and the ordinate represents the X-ray diffraction intensity. No obvious sharp diffraction peaks were found in Fig. 10, and there was no obvious change in the spectrum before and after heating, which indicates that the substance had not undergone the phase change. This shows that there was no violent chemical reaction during the heating and molding process of biomass materials at $230{ }^{\circ} \mathrm{C}$, and the essential changes of biomass materials had not occurred.

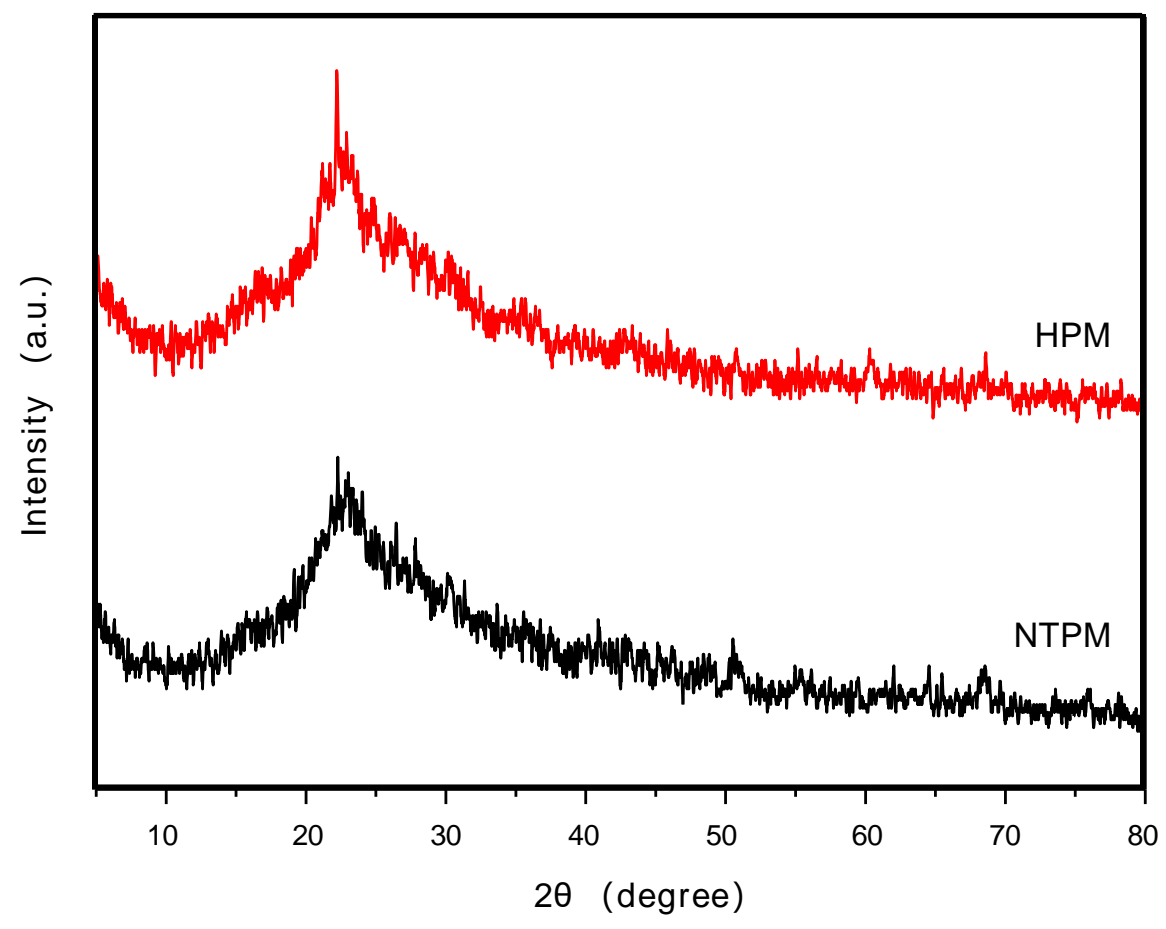

Fig. 10. XRD images of NTPM and HPM samples 


\section{FTIR Results and Discussions}

Figure 11 is the FTIR image of the NTPM and HPM samples. The blue line in the figure is the diffraction result of the NTPM sample, and the orange line is the diffraction result of the HPM sample. The abscissa is wavenumbers, and the ordinate is absorbance. The infrared diffraction patterns of the two samples were not significantly different, indicating that there was no obvious molecular bond breakage in the structure and composition of the biomass before and after heating. The above test results show that the thermoforming method at $230{ }^{\circ} \mathrm{C}$ did not change the structure of the original material (Fig. 11).

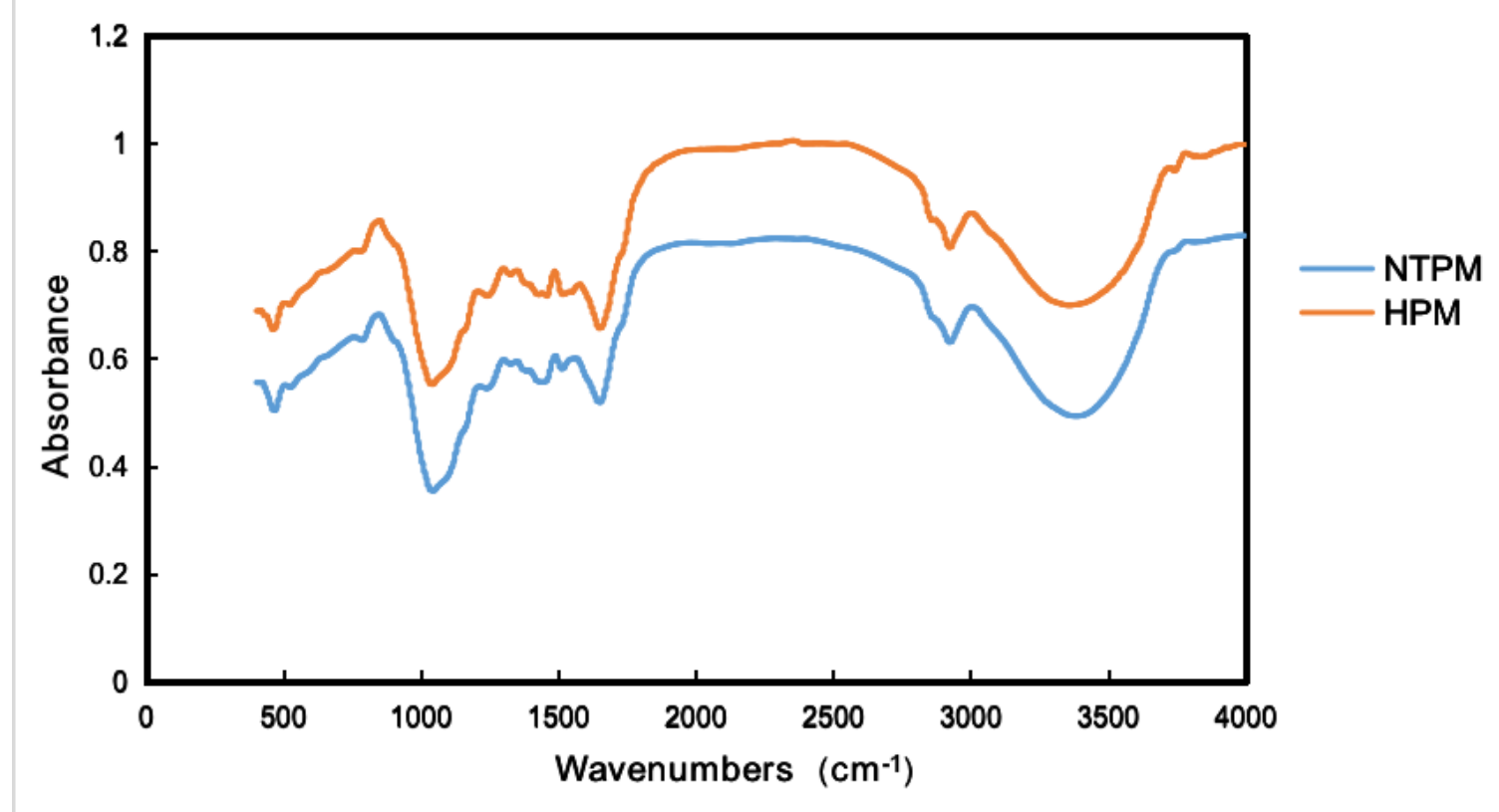

Fig. 11. FTIR images of NTPM and HPM samples

\section{CONCLUSIONS}

1. A new method was developed to manufacture biomass seedling trays with cow dung. The procedure involved heating above the glass transition temperature of the lignin present in the cow dung. The seedling trays prepared using this method met the replanting needs of maize seedlings.

2. The stem fibers in cow dung were compressed together to generate a mechanical setting force at the beginning of the hot-press molding process. When the lignin in the cow dung reached the softening temperature, the flow was generated under the action of internal force, such that the gaps between the fibers and the laminated inlay structure were filled and enclosed. After cooling, the lignin in the seedling tray no longer flows and has changed to a solid form. At this time, the seedling tray has its final shape.

3. The strength of the seedling tray after molding mainly came from the mechanical setting force of the laminated inlay of the stalk fibers in the seedling tray. Lignin adhesion and enclosing played a role in protecting and reducing the damage of water infiltration to the laminated inlay structure but had little effect on improvement in strength. 
4. Moisture in the seedling tray hindered the filling of gaps between stem fibers in cow manure with lignin during the molding process, and thus reduced the protective effect of lignin on the laminated setting structure of stem fibers in cow dung. Therefore, under the premise that the material can be completely filled in the mold, a lower moisture content resulted in better strength and water resistance of the seedling tray.

\section{ACKNOWLEDGMENTS}

This research was supported by Guiding Science and Technology Plan Project of Daqing (No. zd-2019-37), Talent Research Startup Plan of Heilongjiang Bayi Agricultural University (No. XYB201919), the specially funded scientific research project of the public welfare industry (agriculture) of the Ministry of Agriculture of the People's Republic of China (Grant No. 201503116-04-04) on the mechanized farming mode of state-owned farm's corn growing area, Study on Preparation Method and Forming Mechanism of Corn Transplanting Biomass Seedling Pan (Grant No. LH2019E073) of Heilongjiang Natural Science Fund Project, and the innovative talent team of Heilongjiang Bayi Agricultural University. Natural Science Program of Heilongjiang Bayi Agricultural University (No. ZRCPY201814).

\section{REFERENCES CITED}

Anthony, W. B. (1970). "Feeding value of cattle manure for cattle," Journal of Animal Science 30(2), 274-277. DOI: 10.2527/jas1970.302274x

Bai, X. H., Li, F., and Zhang, L. Z. (2008). "Experimental study on straw extrusion molding nursery," Journal of Agricultural Mechanization Research 2, 136-138. DOI: 10.3969/j.issn.1003-188X.2008.02.042

Chen, Z. Y. (2007). "Experimental study on hot pressing of straw raw materials for nursery," Shenyang Agricultural University, 1-2. DOI: 10.7666/d.y1171973

Eghball, B. (2000). "Nitrogen mineralization from field-applied beef cattle feedlot manure or compost," Soil Science Society of America Journal 64(6), 2024-2030. DOI: 10.2136/sssaj2000.6462024x

Espert, A., Vilaplana, F., and Karlsson, S. (2004). "Comparison of water absorption in natural cellulosic fibres from wood and one-year crops in polypropylene composites and its influence on their mechanical properties," Composites Part A: Applied Science and Manufacturing 35(11), 1267-1276. DOI: 10.1016/j.compositesa.2004.04.004

Fang, X. F. (2010). "Current status and development trend of transplanting machinery technology in China," Agricultural Machinery 10(1), 35-36. DOI:

10.16167/j.cnki.1000-9868.2010.01.018

Fukushima, R. S., and Hatfield, R. D. (2004). "Comparison of the acetyl bromide spectrophotometric method with other analytical lignin methods for determining lignin concentration in forage samples," Journal of Agricultural and Food Chemistry 52(12), 3713-3720. DOI: 10.1021/jf0354971

GB/T 16491 (2008). "Electronic universal testing machines," Standardization Administration of China, Beijing, China.

Hatakeyama, H., and Hatakeyama, T. (2009). "Lignin structure, properties, and 
applications," in: Biopolymers, Springer, Berlin, Heidelberg, pp. 1-63. DOI: 10.1007/12_2009_12

ISO 14125 (1998). "Fibre-reinforced plastic composites - Determination of flexural properties," Japan Plastics Industry Federation, Tokyo, Japan.

Lebo, Jr., S. E., Gargulak, J. D., and McNally, T. J. (2002). "Lignin,” in: Encyclopedia of Polymer Science and Technology, 3. DOI: 10.1002/0471440264.pst179

Li, L.-H., Wang, C., Zhang, X.-Y., and Li, G.-Y. (2014). "Improvement and optimization of preparation process of seeding-growing bowl tray made of paddy straw," International Journal of Agricultural and Biological Engineering 7(4), 13-22. DOI: 10.3965/j.ijabe.20140704.002

Lin, S. Y., and Dence, C. W. (2012). Methods in Lignin Chemistry, Springer Science and Business Media, Berlin, Germany.

Maximova, N., Österberg, M., Koljonen, K., and Stenius, P. (2001). "Lignin adsorption on cellulose fibre surfaces: Effect on surface chemistry, surface morphology and paper strength," Cellulose 8(2), 113-125. DOI: 10.1023/A:1016721822763

Nennich, T. D., Harrison, J. H., Vanwieringen, L. M., Meyer, D., Heinrichs, A. J., Weiss, W. P., St-Pierre, N. R., Kincaid, R. L., Davidson, D. L., and Block, E. (2005). "Prediction of manure and nutrient excretion from dairy cattle," Journal of Dairy Science 88(10), 3721-3733. DOI: 10.3168/jds.S0022-0302(05)73058-7

Nunomura, O., Kozai, T., Shinozaki, K., and Oshio, T. (2016). "Seeding, seeding production and transplanting," in: Plant Factory, Academic Press, Berlin, Germany, pp. 223-235. DOI: 10.1016/B978-0-12-801775-3.00018-4

Rumpf, H. C. H. (1970). "Zur theorie der zugfestigkeit von agglomeraten bei kraftübertragung an kontaktpunkten [On the theory of tensile strength of agglomerates during force transmission at contact points]," Chemie Ingenieur Technik 42(8), 538-540. DOI: 10.1002/cite.330420806

Rumpf, H. C. H., and Gupte, A. R. (1971). "Einflüsse der porosität und korngrößenverteilung im widerstandsgesetz der porenströmung [Influences of the porosity and grain size distribution in the resistance law of the pore flow]," Chemie Ingenieur Technik - CIT 43(6), 367-375. DOI: 10.1002/cite.330430610

Salmén, L. (1984). "Viscoelastic properties of in situ lignin under water-saturated conditions," Journal of Materials Science 19(9), 3090-3096. DOI: 10.1007/BF01026988

Sammond, D. W., Yarbrough, J. M., Mansfield, E., Bomble, Y. J., Hobdey, S. E., Decker, S. R., and Vinzant, T. B. (2014). "Predicting enzyme adsorption to lignin films by calculating enzyme surface hydrophobicity," Journal of Biological Chemistry 289(30), 20960-20969. DOI: 10.1074/jbc.M114.573642

Sen, S., Patil, S., and Argyropoulos, D. S. (2015). "Thermal properties of lignin in copolymers, blends, and composites: A review," Green Chemistry, 17(11), 48624887.DOI: $10.1039 / \mathrm{C} 5 \mathrm{GC} 01066 \mathrm{G}$

Song, Y., Hu, R., Li, J., Wang, Z., and Shi, L. (2002). "Using biogas technology to control the pollution of large and medium-sized livestock and poultry farms," China Energy (12), 16-18. DOI: 10.3969/j.issn.1003-2355.2002.12.003

Sreekrishnan, T. R., Kohli, S., and Rana, V. (2004). "Enhancement of biogas production from solid substrates using different techniques-A review," Bioresource Technology 95(1), 1-10. DOI: 10.1016/j.biortech.2004.02.010

Street, R. L., Watters, G. Z., and Vennard, J. K. (1996). Elementary Fluid Mechanics, John Wiley \& Sons, New York, New York, USA, pp. 757. 
Sun, Q. X., Zhang, R. J., and Dong, Y. P. (2009). "Simulation analysis of compressing molding under general condition for straw biomass based on ANSYS," Transactions of the Chinese Society for Agricultural Machinery 40(12), 130-134. DOI: 10.3969/j.issn.1000-1298

Tumuluru, J. S. (2018). "Effect of pellet die diameter on density and durability of pellets made from high moisture woody and herbaceous biomass," Carbon Resources Conversion 1(1), 44-54. DOI: 10.1016/j.crcon.2018.06.002

Wei, Z., Niu, Z.-J., Li, L.-H., and Hou, Y.-R. (2015). "Design and optimization of seeding-feeding device for automatic maize transplanter with maize straw seedingsprouting tray," International Journal of Agricultural and Biological Engineering 8(6), 1-12. DOI: 10.3965/j.ijabe.20150806.1113

Whitehead, D. C., and Raistrick, N. (1993). "Nitrogen in the excreta of dairy cattle: Changes during short-term storage," The Journal of Agricultural Science 121(1), 7381. DOI: $10.1017 / \mathrm{S} 0021859600076814$

Xiao, Z., Li, Y., Wu, X., Qi, G., Li, N., Zhang, K., Wang, D., and Sun, X. S. (2013). "Utilization of sorghum lignin to improve adhesion strength of soy protein adhesives on wood veneer," Industrial Crops and Products 50, 501-509. DOI: 10.1016/j.indcrop.2013.07.057

Yan, H. Z., Liu H. H., Xie Z. Q., and Yu M. J. (2009). "Experimental study on straw forming technology," Journal of Southwest University: Natural Science Edition, 11, 133-139. DOI: 10.1016/j.jsunse.2009.11.00

Zhang, J. Z., and Zhang, Y. (2000). "A breakthrough in new technologies for high yield of corn - plastic floppy disk seeding transplanting," Tianjin Agriculture and Forestry Science and Technology 2000(5), 11-12. DOI: 10.16013/j.cnki.10020659.2000.05.005

Zhao, X. M., and Gong, Y. S. (2000). "Feeding value and research prospects of livestock and poultry manure reclaimed feed," Journal of Animal Husbandry and Veterinary Medicine 19(2), 20-22. DOI: 10.3969/j.issn.1004-6704.2000.02.007

Article submitted: March 7, 2019; Peer review completed: April 20, 2019; Revised version received and accepted: March 8, 2021; Published: March 26, 2021.

DOI: $10.15376 /$ biores.16.2.3543-3562 